\title{
Work in progress - A Mixed-methods Approach to Developing an Instrument Measuring Engineering Students' Positive Ethical Behavior
}

\author{
Matthew A. Holsapple, Cynthia Finelli, Donald Carpenter, Trevor Harding and Janel Sutkus \\ mapple@umich.edu, cfinelli@umich.edu, carpenter@ltu.edu, tharding@calpoly.edu,jsutkus@.cmu.edu
}

\begin{abstract}
Ethics education and the drive to produce ethical professional engineers is an important focus of one body of research on engineering education. This research often defines the positive outcome of ethics education as students and professional engineers choosing not to engage in unethical behavior. This paper discusses a portion of a larger research project and details efforts to identify and validate a definition of ethical behavior that includes the decision to engage in a positive behavior, defined as a service to a larger community. Through a series of interviews and focus groups with engineering administrators, faculty, and students, the authors attempt to confirm the construct validity of service participation as ethical behavior. They also investigate the validity of the aspects of service participation to be included as a part of a national survey on engineering ethics education practices and outcomes. They then discuss the final steps that will be taken to test and further validate the development of the service participation portion of the survey.
\end{abstract}

Index terms: Validity, ethics, focus groups and interviews, qualitative data collection, service, survey development

\section{INTRODUCTION}

The Survey of Engineering Ethical Development (SEED) is an NSF-funded research project being conducted by the $E^{3}$ Team (Exploring Ethical Decision-Making in Engineering, http://www.engin.umich.edu/research/e3/index.html). The goal of the project is to determine the educational practices and cultural aspects that promote ethical development among engineering students. As part of the project, the authors are currently developing a survey that will assess student's campus experiences, exposure to different kinds of ethics education, and ethical development. The SEED will be administered to 4,000 engineering undergraduate students at 20 institutions. This paper will discuss the process of developing a section of the survey to assess positive behavioral aspects of students' ethical development.

Much research into engineering ethics education practices has focused on assessments of in-class learning [1]; however, a small body of research has begun to examine student behavior as an outcome. Most investigations into students' ethical behaviors have looked specifically at negative behaviors, i.e., ethical flaws. The most common way of operationalizing this negative behavior is cheating on academic work [2]. Academic cheating is seen as a valid measure of unethical behavior because the act of cheating requires a decision to engage in a behavior that violates established ethical standards. Additionally, unethical behavior by professional engineers has been linked to cheating on academic work while an undergraduate [3].

We believe that simply examining unethical behaviors does not tell the entire story. To be an ethical engineer is not simply to avoid enacting unethical behaviors, but also to proactively engage in behaviors that represent the tenets of ethical engineering practice. This paper describes ongoing research that attempts to answer two research questions:

1. Is there support for the construct validity of using students' service activities as a positive behavioral aspect of ethical development?

2. What are the specific survey items that will assess a student's participation in service activities?

\section{METHODOLOGY}

We conducted focus groups and personal interviews at four engineering programs, in order to capture domains to be studied with the survey, determine the dimensions that comprise each domain, and identify appropriate wordings to capture each dimension [4]. At each institution, a team of two researchers conducted personal interviews with senior administrators $(n=8)$, and the team conducted a focus group comprised of students $(n=24)$ and one comprised of faculty members $(n=25)$. Except for the student focus groups having a higher proportion of female students, focus group demographics roughly mirrored those of engineering students and faculty nationwide [5]. In the focus groups and interviews, the domain of service activities - defined in the protocols as "activities that largely were designed to help other people, for which student volunteers received no pay, but may have received credit" - was predetermined; thus the focus group was used to ask participants their view on the validity of using service participation to assess ethical development. The protocols also included questions addressing both the second and third purposes above.

The authors used an adapted open-coding constant comparative method to analyze the data [6]. They identified 
participants who discussed the validity of the construct as a way to answer the first research question. To address the second question, they categorized the service activities into themes and then used the themes to develop survey items.

\section{RESULTS}

\section{Construct Validity}

The construct of service participation was chosen for three main reasons. First, much like academic dishonesty in college has been shown to correlate with anti-social behaviors in graduates, research has shown that participating in service activities in college is correlated to prosocial behaviors in graduates [7]. Second, the profession of engineering has begun to embrace service to a larger community, with some engineering disciplines including service to the larger community within their codes of professional conduct. Finally, service participation is particularly salient within students' everyday context; there is no shortage of service opportunities on most college campuses, making this a common activity.

Respondents in the interviews and focus groups supported the construct validity of assessing students' service participation as a measure of their ethical development. For example, one engineering professor said,

"I'm thinking about the first canon of engineering ethics codes which is to hold paramount the health, safety and welfare of the public. So another way of looking at it is that, in that way, everything that engineers do is really service because you're serving the larger community in your work."

Students agreed with this sentiment. A senior electrical engineering student, referring to a class project focused on service, said:

'I think my project is a service to society in that it's furthering technology and it will, in the long run, save lives if it ... is successful, but I think most people think of service as a service to the community."

Other students and faculty echoed these ideas, providing support for the validity of service participating as part of the construct of ethical behavior.

\section{Item Validity}

After confirming the construct validity of service participation as a measure of positive ethical behavioral, we then identified the specific service behaviors and activities in which students engage by studying the transcript data. Two main themes emerged: (1) who the students were serving through the activity (the local community, younger students, the elderly, etc) and (2) through what affiliation they were doing the service (through different kinds of student groups, as part of a non-class-related project with a professor, or as part of a class project). These themes will be used to generate service behavior items for the national survey.

\section{NEXT STEPS}

To continue validation, we will engage in a two-phase survey testing process. First, we will administer the survey to a limited number of students at two institutions serving different types of students. The researchers will engage in cognitive interviewing, a common practice in survey methodology to test the appropriateness of validity of survey items and the clarity of wording in order to avoid measurement error. As part of this process, students will be asked to think aloud as they complete the service-related questions, helping the researchers to understand the thought process for each of the questions. Second, in the fall of 2009, an online version of the SEED will be administered to students at a third institution. Responses from this administration will be analyzed using factor analysis, regression, and other inferential statistical methods to test the reliability, internal validity, and predictive validity of the service behavior section of the instrument.

In the spring of 2010, researchers will administer the final version of the survey to 4,000 engineering undergraduate students attending 20 institutions. Analysis and dissemination of results will follow.

\section{REFERENCES}

1. Harding, T., Finelli, C., Carpenter, D., \& Mayhew, M. "Examining the underlying motivationsof engineering undergraduates behavior ethically," American Society for Engineering Education, 2006.

2. Carpenter, D., Harding, T., Finelli, C, Montgomery, S. \& Passow, H.

"Engineering students' perceptions of and attitudes toward cheating," Journal of Engineering Education, 2006

3. Harding, T., Carpenter, D., Finelli, C., \& Passow, H. "Does academic dishonesty relate to unethical behavior in professional practice?" Science and Engineering Ethics, 2004.

4. Morgan, D., Focus groups as qualitative research, 1997.

5. Pieronek, C., Uhran, J., McWilliams, L., \& Silliman, S. “A demographic characterization of first-year engineering students," American Society for Engineering Education, 2006.

6. Corbin, J. \& Strauss, A., The basics of qualitative research: Technique and procedures for developing grounded theory, 2008.

7. Pascarella, E. \& Terenzini, P. How college affects students. (2005)

\section{AUTHOR INFORMATION}

Matthew A. Holsapple, Doctoral Student, University of Michigan,mapple@umich.edu.edu.

Cynthia Finelli, Director, Center for Research on Learning and Teaching, University of Michigan, cfinelli@umich.edu

Donald Carpenter, Associate Professor, Civil Engineering, Lawrence Technological University, carpenter@ltu.edu Trevor Harding, Associate Professor, California Polytechnic State University, tharding@calpoly.edu

Janel Sutkus, Director of Institutional Research and Analysis, Carnegie Mellon University, jsutkus@cmu.edu 